\title{
Spatially explicit detection of predation on individual pinnipeds from implanted post-mortem satellite data transmitters
}

\author{
Markus Horning ${ }^{1, *}$, Jo-Ann E. Mellish ${ }^{2,3}$ \\ ${ }^{1}$ Department of Fisheries and Wildlife, Marine Mammal Institute, Oregon State University, 2030 SE Marine Science Drive, \\ Newport, Oregon 97365, USA \\ ${ }^{2}$ Alaska Sea Life Center, 301 Railway Ave., Seward, Alaska 99664, USA \\ ${ }^{3}$ School of Fisheries and Ocean Sciences, University of Alaska Fairbanks, Alaska 99775, USA
}

\begin{abstract}
To directly determine mortality and predation in the endangered western Steller sea lion Eumetopias jubatus, we deployed implanted, satellite-linked post-mortem data transmitters in 21 juveniles. Data recovered from 4 of 5 detected mortalities exhibited precipitous drops in ambient temperatures followed by immediate onset of transmissions $(\mathrm{N}=3)$, or gradual cooling and delayed transmissions $(\mathrm{N}=1)$. Precipitous drop data sets were classified as acute death at sea by trauma. A model to estimate algor mortis (body cooling) as a function of mass and ambient conditions was validated through simulations on 4 carcasses. Model outputs suggest that cooling rate masses can be qualitatively distinguished if well outside the prediction uncertainties. The observed gradual cooling rate was best described by a modeled mass one-sixth the animal's mass at release, supporting the classification of the fourth event as acute death at sea by trauma. This suggests that at least 4 in 5 detected mortalities likely represent acute deaths at sea, probably due to predation. We conclude that precipitous drop events with immediate transmissions can be classified as acute death likely by predation, but gradual cooling events with delayed transmission should be reviewed on a case-by-case basis. In 3 cases that provided both ante-mortem and post-mortem locations from external and implanted transmitters, respectively, these differed by less than $17 \mathrm{~km}$, illustrating that this technique provides spatially explicit data of predation on individual sea lions.
\end{abstract}

KEY WORDS: Predation · Mortality · Algor mortis · Telemetry · Eumetopias jubatus · Steller sea lion Resale or republication not permitted without written consent of the publisher

\section{INTRODUCTION}

The accurate detection and quantification of predation in mammalian marine meso-predators, in particular pinnipeds, is vital for the development of effective conservation and management measures (see Springer et al. 2003, Williams et al. 2004, Frank et al. 2007, NMFS 2008). Due to the predominantly pelagic nature and longevity of marine mammals, this problem has been labeled as 'empirically intractable' (Williams et al. 2004). To overcome this constraint, we developed an implantable telemetry device capable of postmortem data transmissions via satellite (Horning \& Hill 2005) in collaboration with Wildlife Computers (Redmond, Washington).
Mortality transmitters are a well-established tool to determine survival rates in wild animals (e.g. Neely \& Campbell 1973, Bjärvall \& Franzén 1981, Vreeland et al. 2004, Haines et al. 2005). Conventional mortality transmitters are externally attached and typically utilize VHF radio transmission. However, external units do not remain attached beyond the annual molt on pinnipeds and seabirds, limiting monitoring to a maximum of 1 yr. Implantation of mortality transmitters avoids long-term attachment problems, and such devices have been successfully used on a wide range of marine endotherms (see Horning et al. 2008). However, reception range and, thus, area coverage from VHF implants is reduced compared to external devices. Transmitting life span is still limited to 2 to $3 \mathrm{yr}$ for reasonably sized 
units. The newly developed Life History Transmitters (LHX tags) use satellite links for post-mortem data recovery. Satellite-linked data loggers, using the Service ARGOS system aboard NOAA satellites for obtaining location fixes and transmission of stored data, have been extensively used on oceanic vertebrates (see Horning \& Hill 2005). At present, however, transmission to a satellite from reasonably sized, fully implanted devices is not feasible. Instead, LHX tags record data from up to 5 built-in sensors to monitor behavior and determine the state of an instrumented animal, but do not transmit while the animal is alive. Mortality events are detected by LHX tags when pre-set temperature thresholds are crossed, triggering the time and date of death to be stored in memory. Subsequently, LHX tags transmit stored data to orbiting satellites, once the positively buoyant devices have been released from a decomposing or partially consumed body. Through the absence of any transmissions until after death and release of the device, battery life is greatly extended to well beyond $5 \mathrm{yr}$, typically 8 to $10 \mathrm{yr}$ or longer (Horning \& Hill 2005). One complication resulting from the reliance on end-of-life transmissions for all data recovery is the inability to transmit periodic 'alive' signals used in conventional mortality transmitters to verify proper transmitter operations. This necessitates accurate determination of tag failure rates. To accomplish this task, dual LHX tags are deployed in implanted animals. In addition to increasing data recovery likelihood, the ratio of single to dual tag returns is used for the estimation of tag failure rates.

Algor mortis, the cooling of endotherm bodies following death, has been used in human forensic pathology to estimate otherwise unknown time of death for bodies of a known mass under a variety of circumstances (Henssge 1988, Mall et al. 2005). Curves derived from Newton's law of cooling have been theoretically modeled (Marshall \& Hoare 1962a-c), and have been modified and empirically tested on cadavers and dummy bodies (Henssge 1995). Equations describing such cooling have been adapted to deal with a wide range of insulating properties on the surface of bodies, ambient temperatures, and ambient media (Henssge 1988, 1995, Mall et al. 2005). These equations can be solved for the mass of the cooling body when time of death and cooling curves are available. This led us to program LHX tags to transmit cooling curves recorded in $30 \mathrm{~min}$ increments following detected mortality events for periods up to $24 \mathrm{~h}$.

Here we report on the suitability of data recorded across mortality events detected and subsequently transmitted from 5 implanted Steller sea lions Eumetopias jubatus to classify detected mortalities into acute, traumatic events, or non-acute events, for the purpose of quantifying predation.

\section{MATERIALS AND METHODS}

Animal telemetry. To directly measure mortality and predation in the endangered western Steller sea lion, we deployed LHX tags (Horning \& Hill 2005) in 21 juveniles $(\mathrm{N}=5$ females and 16 males) from 2005 through 2008 in the Kenai Fjords - Prince William Sound (KF-PWS) region of the Gulf of Alaska. Animals were captured in the wild, transported to and held in temporary captivity at a quarantined facility at the Alaska Sea Life Center (Seward, AK) for periods of 6 to $12 \mathrm{wk}$, and subsequently released into the wild (Mellish et al. 2006). Single ( $N=2$ sea lions) or dual LHX tags $(\mathrm{N}=19)$ were surgically implanted into the abdominal cavity under inhalant gas anesthesia (Horning et al. 2008). All animals were monitored for health and clinical chemistry indicators during captivity, and had to meet previously established rigorous health criteria prior to release (Mellish et al. 2006, 2007). All animals were monitored following their release via externally attached, satellite-linked data transmitters (Mellish et al. 2007, Thomton et al. 2008), and through opportunistic re-sighting of hot-iron brand markings $(N=20)$ or plastic flipper tags $(N=1)$. Captive monitoring indicated non-significant white cell elevations, as well as significant increases in lympho- and monocytes, globulins, and haptoglobin concentrations after implant surgeries. All responses were as expected for normal wound healing, with a return to baseline levels (pre-surgery or at-intake) within $45 \mathrm{~d}$ of procedures, and prior to release (Mellish et al. 2007). From this previously observed return to baseline values in all monitored parameters, a $45 \mathrm{~d}$ post-surgery survival criterion was established for inclusion of animals in the study. Post-release tracking data revealed no significant differences in diving and ranging behavior between implanted and non-implanted animals (Mellish et al. 2007, Thomton et al. 2008). Minimum confirmed survival after surgery for the 21 implanted animals was $334 \pm 72 \mathrm{~d}$ (mean $\pm \mathrm{SEM}$, range 68 to 1325).

Estimation of uplink failure rates, correction factors, and survival rates. For the purpose of determining the possible effect of LHX transmitters and implant procedures on mortalities, we compared survival rates determined from LHX returns to rates provided by the National Marine Mammal Laboratory (NMML) of the National Marine Fisheries Service. To estimate survival rates from LHX tag data, detected events need to be corrected for failure of devices to successfully uplink to the ARGOS system. This failure derives from the combination of technical transmitter faults and the failure of transmissions from functional LHX tags to be received by satellites due to unpredictable operational constraints (i.e. tag lodged under a rock or periodically submerged in the intertidal with only short view of the 
sky during times of limited satellite coverage). These constraints directly result from the concept of postmortem transmissions (Horning \& Hill 2005). To provide an initial estimate of uplink failure rates, 2 tags were implanted in 19 of 21 experimental subjects. From the ratio of single to dual returns, the uplink failure probability $P_{\mathrm{f}}$ was calculated as $P_{\mathrm{f}}=C_{\mathrm{s}} /\left(C_{\mathrm{s}}+2 C_{\mathrm{d}}\right)$ where $C_{\mathrm{s}}$ is the count of single returns, and $C_{\mathrm{d}}$ is the count of dual returns. A correction factor $F_{\mathrm{C}}$ can then be derived as $F_{\mathrm{c}}=1 /\left(1-P_{\mathrm{f}}^{2}\right)$, and the corrected mortality counts $M_{\mathrm{C}}$ are calculated as $M_{\mathrm{C}}=F_{\mathrm{c}}\left(C_{\mathrm{s}}+C_{\mathrm{d}}\right)$.

We estimated survival rates from $M_{\mathrm{C}}$ and cumulative exposure days $\left(D_{\mathrm{e}}\right)$ using a modified Mayfield method (Mayfield 1961). Survival rates for periods of $n$ days were calculated as $\left[1-\left(M_{\mathrm{c}} / D_{\mathrm{e}}\right)\right]^{n}$. For annual survival rates, $n$ $=365.95 \%$ confidence limits were calculated from variance and standard error as per Johnson (1979), but this estimation excludes variance in failure rate estimates due to low sample sizes. Instead, the likely range in $P_{\mathrm{f}}$ within the data set was used, with lower limit estimates based on detected rather than corrected counts, and upper limits based on corrected counts derived from the greatest theoretical value of $P_{\mathrm{f}}$ within actual returns.

We used mark re-sight data collected by the NMML (L. Fritz pers. comm.) for juvenile Steller sea lions, based on $\mathrm{N}=255$ hot-iron brands applied at Seal Rocks (PWS) in 2001, 2003, and 2005, and re-sightings conducted annually from 2002 through 2007. The NMML used the program MARK to estimate age class specific annual survival rates (White \& Burnham 1999). The following annual survival rate (ASR) values were used for males (listed as year of life: mean ASR, 95\% CI): yr 1-2: $0.633,0.450-0.637$; yr 2-3: 0.704, 0.556-0.769; yr 3-4: 0.874, 0.804-0.922; and for females: yr 1-2: 0.727, 0.507-0.686; yr 2-3: 0.786, 0.608-0.807; yr 3-4: 0.915, $0.862-0.949$. To estimate survival rates for a comparable sample size, mix of age classes, sex, and observation time spans as the 19 juvenile sea lions (4 female, 15 male) that received dual LHX implants, we calculated means weighted by the proportion of each sex in the LHX study, and multiplied successive ASRs to obtain rates for 2 successive years. 95\% confidence limits were identically computed as weighted means and products of age class ASR-specific limits.

Estimation of algor mortis. We calculated predicted cooling rates for sea lion bodies as a function of body mass, medium, and ambient temperatures from theoretical models (Marshall \& Hoare 1962a-c) empirically modified for human cadavers and test dummies under a variety of insulating and ambient conditions (Henssge 1988, 1995). Such models are scalable to ambient temperature and body mass (Mall et al. 2005). We used

$$
\mathrm{Q}=\frac{T_{\text {core }}-T_{\text {ambient }}}{T_{0}-T_{\text {ambient }}}=1.25^{B t}-0.25^{5 B t}
$$

where $\mathrm{Q}$ is the standardized temperature quotient from Newton's law of cooling, $T_{\text {core }}$ is the body core temperature at time $t, T_{0}$ is the core temperature at time of death, $T_{\text {ambient }}$ is the temperature of the surrounding medium, and $B$ is the Newtonian cooling coefficient described by

$$
B=-1.2815 \times(C \times \text { Mass })^{-0.625}+0.0284
$$

The empirical correction factor $C$ was parameterized after Henssge (1995) using values of 0.75 for moving air, 0.35 for flowing water, and 0.5 for still water. Eq. (1) yields predicted cooling curves of core temperatures $T_{\text {core }}\left({ }^{\circ} \mathrm{C}\right)$ as a function of time $t(\mathrm{~h})$ since death, for a given Mass $(\mathrm{kg})$. Confidence limits containing 95\% of variance were estimated as per Henssge (1995), using empirically derived ranges for $t$ as a function of $\mathrm{Q}$.

Laboratory simulations. To verify algor mortis estimates obtained as outlined above, for a range of body mass values and conditions, we used 4 California sea lion Zalophus californianus carcasses obtained through regional stranding networks. A previously collected, frozen $14 \mathrm{~kg}$ male yearling sea lion was kindly provided by the Oregon Marine Mammal Stranding Network (OMMSN, Newport, OR). This animal was emaciated with minimal subcutaneous blubber (<8 mm ventral abdominal subcutaneous blubber), and had probably died from starvation. A previously collected, frozen $30 \mathrm{~kg}$ male yearling sea lion was kindly provided by The Marine Mammal Center (Sausalito, CA). This animal was in good body condition (38 mm ventral abdominal subcutaneous blubber) and had died from acute trauma, probably a shark bite that had removed skin, blubber, and some muscle from a lateral portion of the central torso, as well as about half of one fore flipper. The abdominal region remained intact. A $70 \mathrm{~kg}$ adult female sea lion was euthanized at the Alaska Sea Life Center for reasons unrelated to this project. The animal was in apparent good body condition but presented with likely terminal neurological symptoms probably related to acute domoic acid toxicity (Gulland et al. 2002). A sub-adult male $184 \mathrm{~kg}$ sea lion was euthanized at The Marine Mammal Center for reasons unrelated to this project. The animal was in excellent body condition with >50 mm ventral abdominal subcutaneous blubber, but was blind and exhibited likely terminal neurological symptoms possibly related to domoic acid toxicity.

The 2 frozen carcasses were thawed over a period of $48 \mathrm{~h}$, whereas the bodies of the 2 larger animals were used immediately following euthanasia. Through a ventral abdominal incision similar to tag insertion surgery (Horning et al. 2008), 1 LHX tag and 2 resistive temperature sensors linked via cable to external monitors (14 and $30 \mathrm{~kg}$ carcasses) or 2 LHX tags only (184 kg animal) were inserted into the abdominal cav- 
ity. For the $70 \mathrm{~kg}$ animal, a single temperature radiotransmitter pill (model STP, Wildlife Computers) was inserted into the abdominal cavity. The insertion site was sutured accordingly to mimic implant surgery, with additional cyano-acrylate surgical glue applied to ensure waterproof closure. The 2 smaller carcasses were then warmed to a core temperature of $42^{\circ} \mathrm{C}$. Subsequently, the carcasses were gradually allowed to cool in air at a temperature of $10^{\circ} \mathrm{C}$, to a core temperature of $37^{\circ} \mathrm{C}$. This over-warming and subsequent passive cooling resulted in a realistic temperature gradient from core to periphery within the 2 previously frozen sea lion carcasses. The 2 smaller carcasses were then placed into a 2001 refrigerated constant temperature water bath regulated to $4.5^{\circ} \mathrm{C}$. The $184 \mathrm{~kg}$ carcass was placed into a $10000 \mathrm{l}$ water tank with water temperatures held between $12.5^{\circ} \mathrm{C}$ and $13.5^{\circ} \mathrm{C}$ by periodic addition of ice. The $70 \mathrm{~kg}$ carcass was placed on an exterior concrete deck at the Seward facility and exposed to ambient air. Cooling rates in water were recorded by and subsequently retrieved from the LHX tags. The cooling rate in air was recorded by an external receiver / data logger from temperature data received from the transmitter pill. The data logger also recorded the temperature of ambient air.

To simulate cooling rates corresponding to the ingestion of an LHX tag by a poikilotherm predator (i.e. shark), tags stabilized at $T_{0}=37^{\circ} \mathrm{C}$ were inserted into gastric tissue of one of the sea lion carcasses held at $4.5^{\circ} \mathrm{C}$.

Cooling rates for immediately extruded LHX tags were verified by transferring tags stabilized at $T_{0}=$ $37^{\circ} \mathrm{C}$ to a constant temperature water bath or refrigerator held at $T_{\text {ambient }}$.

Following the cooling rate measurements, the $184 \mathrm{~kg}$ male sea lion carcass was transported to and released in Monterey Bay, CA, in approximately $100 \mathrm{~m}$ of water depth, with the 2 LHX transmitters, to determine time to release of LHX tags from a simulated non-traumatic death at sea.

Analysis. Two state transitions had to be determined for tags exhibiting a precipitous temperature drop, the transition from ante-mortem equilibrium to the onset of post-mortem cooling, and the transition from cooling to steady state (having reached thermal equilibrium in the new environment). Transitions were determined using a method modified after Yaeger \& Ultsch (1989), initially developed for the determination of critical points using continuous, sliding 2-phase regressions. In precipitous cooling events, cooling phases were characterized by only 1 to 4 data points before reaching a new equilibrium, prohibiting the use of contiguous 2-phase regressions. Instead, a discontinuous, sliding split-phase regression bridging a gap in data points representing the state change, was performed.
From both equilibrated extremes, progressively more data points were included towards the state change gap, until the residual sum of squares was minimized. The number of intervals between the 2 phases corresponded to the time required to complete the state change from within the body, to being equilibrated in the environment. Student's $t$-test and Mann-Whitney $U$-test were performed in Systat Version 10 (SPSS). Data are shown as mean \pm SE of the mean (SEM), $\alpha=$ 0.05 , and degrees of freedom (df) are $\mathrm{N}-2$ unless otherwise indicated.

\section{RESULTS}

\section{Detected mortalities}

Data from 8 of 10 LHX tags deployed in 5 animals were received or recovered from November 2005 through February 2009 (Table 1). All 5 deceased animals had survived beyond the $45 \mathrm{~d}$ inclusion criterion $(203 \pm 49 \mathrm{~d}$, range 82 to 369$)$. At least 1 transmitter from each detected mortality successfully uplinked via the ARGOS system, but in only 1 instance did both devices uplink. Four transmitters from 3 mortality events were physically recovered: 2 by search teams sent to transmitting locations and 2 by beachcombers. All 4 recovered devices were structurally sound and in excellent condition, with even the outermost of 3 concentric moisture barriers (Horning \& Hill 2005) uncompromised.

Of the 5 detected mortality events, 1 occurred in PWS, 3 occurred in or near Resurrection Bay (KF region), and 1 occurred in Cook Inlet (Table 1). In 2 of 5 cases (TJ33, TJ47), external transmitters provided locations 1.5 and $3.25 \mathrm{~h}$ prior to the events, and LHX tags provided locations 23 and $4 \mathrm{~h}$ after the events, respectively. In a third case (TJ32), an external location was obtained $46 \mathrm{~h}$ before the event, but the first postevent location was not obtained until $15.6 \mathrm{~d}$ following the event. The mean pre- to post-event distance for these 3 cases was $10.4 \pm 3.1 \mathrm{~km}$. In a fourth case (TJ35), no recent pre-event location was obtained, as the external transmitter had ceased to uplink $87 \mathrm{~d}$ beforehand. In this case, the first location was obtained within $4.4 \mathrm{~d}$ after the event.

\section{Uplink failure and survival rate estimates}

The initial returns from 5 detected mortality events and 1 simulated mortality are insufficient to accurately assess uplink failure rates, but allow the determination of a likely range. Data were obtained from 8 of 10 tags deployed in 5 deceased animals, and from both tags 
Table 1. Eumetopias jubatus and Zalophus californianus. Summary of event data from detected mortalities $(\mathrm{N}=5)$ and carcass testing $(\mathrm{N}=1)$. Post-release (PR) data were collected via externally attached satellite transmitters. Distances are based on class 1 , 2, or 3 ARGOS locations from external (ante-mortem) or LHX (post-mortem, PM) transmitters; for C1, the location of carcass deposition as determined by GPS was used to compute distance to PM locations. PWS: Prince William Sound, KF: Kenai Fjords, CI: Cook Inlet, MB: Monterey Bay; UL: uplinked; R: recovered; na: not applicable

\begin{tabular}{|c|c|c|c|c|c|c|c|c|}
\hline Animal & $\begin{array}{c}\text { Time } \\
\text { tracked } \\
\text { PR (d) }\end{array}$ & $\begin{array}{l}\text { Time } \\
\text { alive } \\
\text { PR (d) }\end{array}$ & $\begin{array}{c}\text { Event } \\
\text { location }\end{array}$ & Tags & $\begin{array}{l}\text { Time from } \\
\text { mortality to } \\
\text { 1st uplink }\end{array}$ & $\begin{array}{c}\text { Time from } \\
\text { last external } \\
\text { to PM } \\
\text { LHX uplink }\end{array}$ & $\begin{array}{c}\text { Distance }(\mathrm{km}) \\
\text { from release to } \\
\text { 1st PM } \\
\text { location }\end{array}$ & $\begin{array}{c}\text { Distance }(\mathrm{km}) \\
\text { last external } \\
\text { to } 1 \mathrm{st} \text { PM } \\
\text { location }\end{array}$ \\
\hline TJ27 & 97 & 336 & PWS & $-/ \mathrm{UL}, \mathrm{R}^{\mathrm{a}}$ & $9 \mathrm{~d}$ & $248 d$ & 192 & 27 \\
\hline TJ32 & 136 & 138 & $\mathrm{KF}$ & $\mathrm{R}^{\mathrm{b}} / \mathrm{UL}^{\mathrm{a}}$ & $15 \mathrm{~d} 18 \mathrm{~h}$ & $17 \mathrm{~d} 15 \mathrm{~h}$ & 27 & 16.5 \\
\hline TJ33 & 124 & 124 & $\mathrm{KF}$ & $\mathrm{R}^{\mathrm{b}} / \mathrm{UL}, \mathrm{R}^{\mathrm{b}}$ & $23 \mathrm{~h}$ & $24.5 \mathrm{~h}$ & 11 & 6 \\
\hline TJ35 & 131 & 222 & $\mathrm{KF}$ & $-/ \mathrm{UL}^{\mathrm{b}}$ & $4 \mathrm{~d} 10 \mathrm{~h}^{\mathrm{c}}$ & $91 \mathrm{~d}$ & 282 & 55 \\
\hline TJ47 & 67 & 67 & $\mathrm{CI}$ & $\mathrm{UL}^{\mathrm{b}} / \mathrm{UL}^{\mathrm{b}}$ & $4 \mathrm{~h} / 4 \mathrm{~h}$ & 7 h 15 min & 98 & $8.8 / 9.0$ \\
\hline $\mathrm{C} 1$ & na & na & MB & $\mathrm{UL}^{\mathrm{b}} / \mathrm{UL}^{\mathrm{b}}$ & $46 \mathrm{~d} / 56 \mathrm{~d}$ & na & & $12.5 / 7.1$ \\
\hline
\end{tabular}

deployed in 1 carcass (Table 1). Only 8 of these tags had uplinked via ARGOS, and 2 tags were recovered by beachcombers before they could uplink. Upon recovery, both tags were in a mode to transmit every tenth day, and depending on when and how the tags were washed ashore, they may only have had few opportunities to uplink prior to physical recovery. The devices were opened in the laboratory to download stored data. No indication of fault was found. During subsequent laboratory bench testing, both devices were re-started and successfully uplinked after simulated mortality events. One of these 2 devices was then used in the field testing of the $184 \mathrm{~kg}$ sea lion carcass in Monterey Bay, where it also successfully uplinked. While both tags did uplink in the laboratory subsequent to their recovery, we cannot assume that they would have uplinked without interference from the recovery location. This leads to 3 potential estimates: (1) assuming neither of these 2 tags would have uplinked, $P_{\mathrm{f}}=0.5 ;(2)$ assuming 1 of the 2 tags would have uplinked, $P_{\mathrm{f}}=0.33$; (3) assuming both tags would eventually have uplinked, $P_{\mathrm{f}}=0.20$. This suggests that $0.2 \leq P_{\mathrm{f}} \geq 0.5$. Within this range, we consider $P_{\mathrm{f}}=0.33 \mathrm{as}$ the most probable scenario for 2 reasons: (1) excluding these 2 mortalities yields $P_{\mathrm{f}}=0.33$ from 4 returns, and (2) the probability of neither tag uplinking for any value $0.2 \leq P_{\mathrm{f}} \geq 0.5$ is always less than $25 \%$, and only $13 \%$ on average. Using an initial $F_{\mathrm{c}}=1.125$ (for $P_{\mathrm{f}}=$ $0.33)$, we estimated that 5.625 mortalities likely occurred.

From 5 detected and 5.625 assumed mortalities over 7155 cumulative exposure days for a subset of 19 animals (4 females and 15 males), we estimated mean survival rates for Years 2 through 4 combined (12 through 48 mo of age) at 0.42 (95\% CI: 0.17 to 0.91 ). Two animals with single LHX tag implants were excluded. We derived a rate of $0.42(95 \%$ CI: 0.22 to 0.47 ) for 255 branded animals of Ages 2 to 4 .

\section{Temperature profiles of detected mortality events}

One event (TJ27) delivered no data other than the date of the event, due to a technical failure in the LHX device. Ante- to post-mortem temperature profiles were recovered from 6 tags and 4 events (Table 1). Five profiles from 3 events exhibited a precipitous temperature decline (Fig. 1). In all 3 events, the devices that successfully uplinked commenced transmissions at the next opportunity, indicating rapid tag extrusion. Since LHX tags are programmed to evaluate initiation of transmissions only once per day at noon, up to $24 \mathrm{~h}$ may elapse between the detection of a mortality event and onset of transmissions. One of 3 transmit protocols is then selected through a heuristic algorithm (Horning \& Hill 2005), resulting in quiescent periods between 1 and $9 \mathrm{~d}$ between transmission episodes. This explains the 4 d delay between mortality detection and first successful uplink in 1 event (TJ35). All 5 precipitous profiles were characterized by peak cooling rates of $-0.75 \pm 0.06^{\circ} \mathrm{C} \mathrm{min}^{-1}$, and by a time between antemortem and post-mortem steady states of $1 \mathrm{~h}(2 \mathrm{sam}-$ pling intervals).

One profile (TJ32) exhibited a single distinct state transition ante- to post-mortem, followed by gradual cooling characterized by a peak initial rate of $-0.16^{\circ} \mathrm{C}$ $\mathrm{min}^{-1}$, and of a shape compatible with Newton's law of cooling (Fig. 2). This device did not uplink, but was physically recovered, and data indicate a delayed extrusion of this tag. The second device from TJ32 did uplink $15 \mathrm{~d}$ after the event, but only an incomplete temperature profile was obtained from this second tag, 


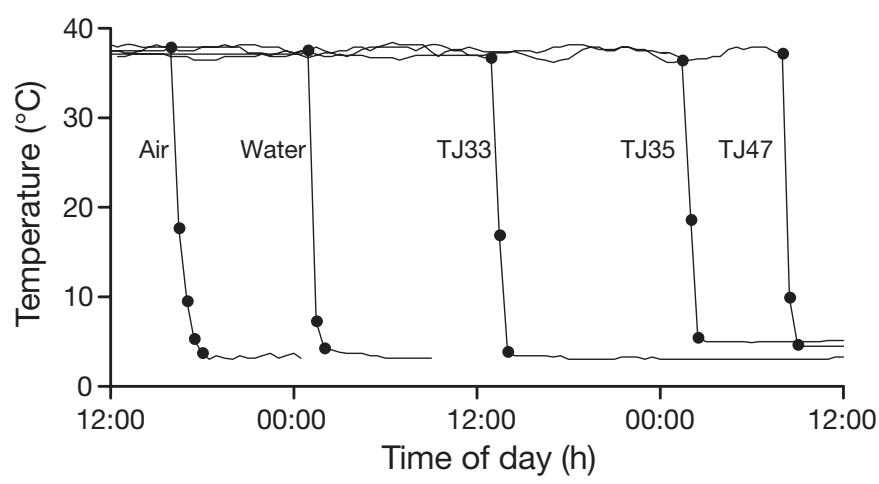

Fig. 1. Eumetopias jubatus. Temperature transitions recorded from 3 mortality events with immediate tag extrusion and from 2 transition simulations into air and water. Temperatures were recorded at 30 min intervals (solid lines). (•) Data points defining state transition periods (see 'Materials and methods'). Only 1 of the 2 identical curves obtained for each of TJ33 and TJ47 are shown

and insufficient data were received to indicate immediate versus delayed tag extrusion.

All devices that successfully uplinked did so initially while floating at sea, based on ARGOS location data, transmitted tag state data, and ambient temperatures at the time of transmission. All of these devices were subsequently washed onto beaches.

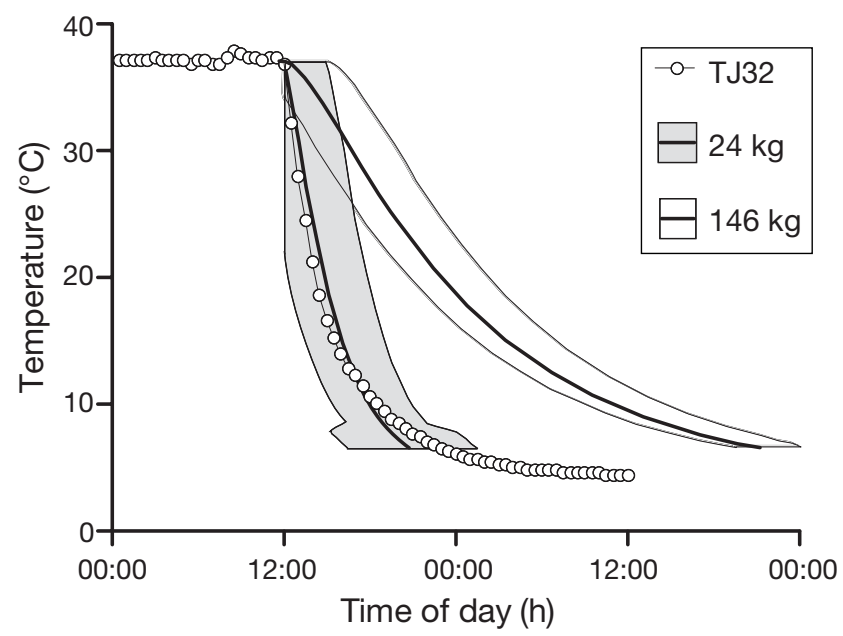

Fig. 2. Eumetopias jubatus. Temperature transition recorded from a mortality event with delayed extrusion of 1 LHX tag (TJ32). Temperatures were recorded at 30 min intervals; 0:00 is local midnight, 12:00 is local noon. Post-event temperatures correspond to sea temperatures for event location. Observed cooling rate for TJ32 (O) corresponds to the predicted algor mortis for a $24 \mathrm{~kg}$ mass of tissue immersed in flowing water of 4 to $5^{\circ} \mathrm{C}$ (solid black line in grey area). Grey shaded area represents $95 \%$ confidence intervals of model output. Predicted algor mortis for a mass equivalent to the $146 \mathrm{~kg}$ at release of animal TJ32 is significantly slower (solid line, transparent outlined area represents $95 \% \mathrm{CI}$ )

\section{Temperature profiles from laboratory simulations, carcass testing, and models}

Experimental tag cooling rates corresponding to immediate extrusion into water and air were characterized through 15 transfers of tags equilibrated at $T_{0}=$ $37^{\circ} \mathrm{C}$ into water and air at $T_{\text {ambient }}=4.5^{\circ} \mathrm{C}$, respectively. These transfers resulted in distinct, characteristic temperature profiles (i.e. Fig. 1). Peak cooling rates were $-0.88 \pm 0.04{ }^{\circ} \mathrm{C} \min ^{-1}$ for water and $-0.63 \pm 0.03^{\circ} \mathrm{C}$ $\mathrm{min}^{-1}$ for air. While the peak rates differed significantly $\left(t_{2,28}=5.42, \mathrm{p}<0.001\right)$, ranges overlapped and thus do not allow unequivocal distinction of events by peak cooling rates. Transition time (time between 2 equilibria) was $1.0 \mathrm{~h}$ for all water transitions, and $1.8 \pm 0.13 \mathrm{~h}$ (range 1.5 to 2.0) for air transitions, allowing an unequivocal distinction of water from air transfer events by transition time (see also Fig. 1).

Three gastric transfers $\left(T_{\text {ambient }}=6.0^{\circ} \mathrm{C}\right)$ to simulate tag ingestion by a poikilotherm predator resulted in peak cooling rates of $-1.06 \pm 0.17^{\circ} \mathrm{C} \mathrm{min}^{-1}$, exceeding even the water transfer rates, presumably because the entire tag was wetted at $T_{\text {ambient, }}$ while for water transfers about one-fourth of the tag floats above water.

Carcass cooling rates varied with carcass mass, ambient medium, and $T_{\text {ambient }}$ (Fig. 3). The smallest carcass with a mass of $14 \mathrm{~kg}\left(T_{\text {ambient }}=4.5^{\circ} \mathrm{C}\right)$ exhibited the highest peak cooling rate of $-0.22^{\circ} \mathrm{C} \mathrm{min}^{-1}$, while the highest rate recorded for the $30 \mathrm{~kg}$ carcass $\left(T_{\text {ambient }}=4.5^{\circ} \mathrm{C}\right)$ was $-0.09^{\circ} \mathrm{C} \mathrm{min}^{-1}$. The $184 \mathrm{~kg}$ carcass $\left(T_{\text {ambient }}=13.0^{\circ} \mathrm{C}\right)$ exhibited a peak rate of $-0.03^{\circ} \mathrm{C}$

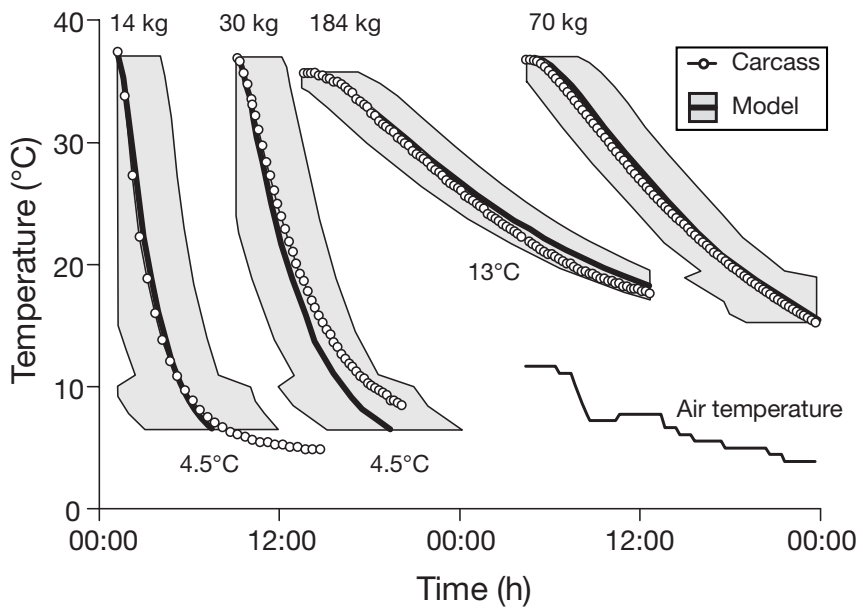

Fig. 3. Zalophus californianus. Comparison of experimental carcass cooling rates $(0)$ to algor mortis model outputs. Two smaller carcasses (14 and $30 \mathrm{~kg}$ ) were cooled in $4.5^{\circ} \mathrm{C}$ water, 1 larger carcass $\left(184 \mathrm{~kg}\right.$ ) was cooled in $13^{\circ} \mathrm{C}$ water. A $70 \mathrm{~kg}$ carcass was cooled in air of varying temperature as indicated. Temperatures were recorded in $30 \mathrm{~min}$ intervals. Grey shaded areas represent $95 \%$ confidence intervals of model outputs (solid black lines) 
$\mathrm{min}^{-1}$. In air, the peak rate for the $70 \mathrm{~kg}$ carcass was $-0.027^{\circ} \mathrm{C} \mathrm{min}^{-1}$.

Algor mortis model outputs were generated for body mass, surrounding medium, and ambient temperature values corresponding to the 4 carcasses tested (Fig. 3), as well as for the closest match to the cooling curve observed for TJ32, and for the body mass of TJ32 at time of release (Fig. 2).

\section{DISCUSSION}

Data returns of 8 devices from 5 animals and 2 from 1 simulated at-sea mortality illustrate that Life History Transmitters are a viable approach for the detection of mortalities in free-ranging sea lions (see Table 1). Previously published control studies have shown that implant procedures are well tolerated and do not alter short term post-release behavior and survival (Mellish et al. 2007, Horning et al. 2008, Petrauskas et al. 2008, Thomton et al. 2008). Within the constraints of a very low sample size, a comparison of preliminary estimates of survival rates derived from LHX tag returns, to rates derived from brand re-sight studies conducted by the NMML (L. Fritz pers. comm.) suggests that implant procedures and LHX tags do not affect long-term postrelease survival to the age of $4 \mathrm{yr}$. Control studies and survival rate estimates combined suggest that beyond the proportion accounted for via the $P_{\mathrm{f}}$-derived correction factor, no additional mortalities went undetected, and that no mortalities were caused by the LHX approach.

Laboratory testing showed that temperature profiles recorded by LHX tags at 30 min intervals can be used to distinguish immediate tag extrusions into water from immediate extrusions into air, based on the time elapsed from mortality / extrusion to reaching equilibrium in the new thermal environment. Data from 4 carcass tests (Fig. 3) combined with data from 1 mortality with delayed tag extrusion (Fig. 2) showed that peak cooling rates can be used to distinguish delayed from immediate air or water extrusion events ( $\mathrm{N}=5$ carcass, $\mathrm{N}=15$ air, $\mathrm{df}=1, U=75.0, \mathrm{p}=0.001)$. Even the highest rate observed in the smallest carcass $\left(-0.22^{\circ} \mathrm{C} \mathrm{min}^{-1}\right)$ was less than half the slowest rate observed for an immediate extrusion into air.

The cooling rates recorded from 4 carcass tests fell within the $95 \%$ confidence limits of algor mortis model outputs for similar masses, ambient media, and temperatures (Fig. 3). This suggests that the model allows a qualitative distinction between body masses and ambient temperatures for actual cooling curves, provided these are located well outside of the predictive uncertainties of the model. If the ambient medium (water or air) can be inferred from final temperatures, these results also suggest that it may be possible to estimate body mass at the time of death.

Three of 4 detected mortalities that delivered temperature data exhibited precipitous temperature drops indicative of immediate tag extrusion into water (Fig. 1). Combined with the onset of transmissions at the very next opportunity, by tags floating in water, this suggests 3 cases of acute death at sea by major trauma. Two of these 3 animals still carried an externally attached satellite data transmitter and exhibited diving behavior comparable to previously monitored, implanted animals (Mellish et al. 2007, Thomton et al. 2008), hours before death.

Data from the fourth detected mortality are more difficult to interpret. The gradual cooling curve and peak rate recorded by 1 LHX tag with delayed extrusion, combined with delayed onset of transmissions by the second tag, initially suggests the possibility of a nonacute death by disease, starvation, or other non-traumatic cause. The observed cooling rate matches Newtonian cooling curves produced by the algor mortis model and by carcass testing, and is distinct from temperature transition signatures expected for immediate extrusion into air, water, or gastric tissue of a poikilotherm predator. The final temperature of the recorded cooling curve corresponded to sea water temperatures in Resurrection Bay at the time of death, suggesting the mortality occurred in water. However, the algor mortis model output most closely matching the recorded cooling rate corresponds to a mass of $24 \mathrm{~kg}$ cooling in water of $4.5^{\circ} \mathrm{C}$. TJ32 had a body mass of $146 \mathrm{~kg}$ at release $138 \mathrm{~d}$ before death. Applying the mean winter growth rate observed for 16 to 20 mo old male sea lions (J. Mellish unpubl. data) of $5 \mathrm{~kg} \mathrm{mo}^{-1}$ suggests a likely mass near $170 \mathrm{~kg}$ at the time of death. This animal was also observed via remote video monitoring system (Maniscalco et al. 2007) $2 \mathrm{~d}$ prior to death. Recorded video images show the animal in apparent good body condition, moving well and with no visually apparent health issues. The last uplink and location from a tracking device externally attached to this animal occurred $46.5 \mathrm{~h}$ prior to death, and dive data suggest no unusual activities. Thus, it is highly unlikely that the mass of TJ32 was substantially below the release mass of $146 \mathrm{~kg}$. The most likely explanation for this event is therefore also acute death at sea by major trauma, with the body of the animal likely dismembered into several pieces, and with 1 tag remaining lodged within a piece of tissue with a mass of approximately $24 \mathrm{~kg}$.

The most likely cause of acute death at sea by major trauma is an attack by a predator that kills and dismembers the prey, leading to: (1) the immediate extrusion of implanted LHX tags into water, or (2) dismemberment of the prey and LHX tags lodged within 
chunks of smaller mass. Transmitter ingestion by a poikilotherm predator should be evident through faster tag cooling rates than for water transfers. Ingestion by a homeotherm predator may be discernible through an analysis of ancillary data. However, simultaneous ingestion of both free-floating LHX tags is deemed unlikely for predators known to dismember their prey. Other possible acute causes of mortality may include entanglement and drowning in fishing gear, shooting, and ship strikes. Such events occur in the Bering Sea - Aleutian Island region, but are rare in the KF-PWS area (Loughlin \& York 2000). Unless shot and entangled animals are promptly dissected, these should not lead to direct tag extrusion and immediate transmissions, or to abrupt transitions to ambient temperatures. Ship strikes on marine mammals are usually described as massive blunt force trauma (Geraci \& Lounsbury 1993), but are considered extremely rare for pinnipeds and are highly unlikely to result in an immediate extrusion (Andersen et al. 2007). Instead, without dissection, all acute and non-traumatic events other than predation should lead to a gradual transition to ambient temperatures as the entire carcass cools, with substantially delayed tag extrusion and onset of transmissions.

The transient ecotype of the killer whale Orcinus orca is the most common predator of pinnipeds in the North Pacific and Gulf of Alaska (Ford et al. 1998, Loughlin \& York 2000, Heise et al. 2003). Predation by salmon sharks Lamna ditropis and Pacific sleeper sharks Somniosus pacificus on Steller sea lions does occur, but is outnumbered 10 to 1 by killer whale predation (Loughlin \& York 2000), and has not been reported for the KF-PWS region. Our data suggest that probably at least 4 of the 5 detected mortalities were caused by predation, most likely by killer whales.

In case of immediate tag extrusion, observed time spans between mortalities and successful uplinks suggest that predation information is spatially explicit, within a radius of about $10 \mathrm{~km}$. This gives spatial information about predation events, as well as a single endof-life location for the host, and may allow determination of larger scale emigration patterns. For the single carcass released in Monterey Bay simulating a nontraumatic death at sea with delayed tag extrusion, distances between carcass deposition location and initial post-mortem locations were 7.1 and $12.5 \mathrm{~km}$ for the 2 transmitters, respectively (Table 1). Even in the case of TJ32, initial post-mortem locations differed from last ante-mortem locations by less than $17 \mathrm{~km}$.

We conclude that the classification of mortalities into acute/traumatic and non-traumatic is possible based on post-mortem transmissions of recorded cooling rates and ancillary data, in particular if LHX tag extrusion is immediate. Events not associated with immedi- ate extrusion should be reviewed on a case-by-case basis. If cooling mass estimates are sufficiently distinct from likely body mass values at the time of death, classification should be possible. However, in case of massive trauma that does not result in dismemberment or mass alteration, a traumatic event may be mis-classified as non-traumatic.

Acknowledgements. This work was supported by North Pacific Marine Research Program (No. 00-0029) and US Department of Commerce (NA17FX1429) grants to M.H. and J.E.M., and by the Alaska Sea Life Center. We thank field teams, husbandry staff, M. Haulena, P. Tuomi, C. Goertz, M. Gray, J. Thomton and J. Nienaber for procedures and assistance, and L. Fritz for providing brand re-sight data. We thank J. Rice of the Oregon Marine Mammal Stranding Network, L. Wheeler, D. Greig, and N. Pussini of The Marine Mammal Center, C. Goertz and J. Skinner of the Alaska Sea Life Center, and L. Petrauskas of the Marine Mammal Institute for providing access to and assisting in work with sea lion carcasses. We thank J. Maniscalco and team at the Alaska Sea Life Center for providing remote video observation information on study animals. Animal work complied with all applicable ethics guidelines and animal welfare laws, and was conducted under National Marine Fisheries Service permits under the US Marine Mammal Protection and Endangered Species Acts Nos. 881-1668, 881-1890, 1034-1887, and ASLC Institutional Animal Care and Use Protocols Nos. 03007, 05-002, 06-001, and 08-005.

\section{LITERATURE CITED}

Andersen MS, Forney KA, Cole TVN, Eagle T and others (2007) Differentiating serious and non-serious injury of marine mammals: report of the serious injury technical workshop, US Department of Commerce, NOAA Tech Memo NMFS-OPR-39

Bjärvall A, Franzén R (1981) Mortality transmitters: an important tool for studying reindeer calf mortality. Ambio 10: $26-28$

Ford JKB, Ellis GM, Barrett-Lennard LG, Morton AB, Palm RS, Balcomb KC (1998) Dietary specialization in two sympatric populations of killer whales (Orcinus orca) in coastal British Columbia and adjacent waters. Can J Zool 76:1456-1471

Frank KT, Petrie B, Shackell NL (2007) The ups and downs of trophic control in continental shelf ecosystems. Trends Ecol Evol 22:236-242

Geraci JR, Lounsbury VJ (1993) Marine mammals ashore: a field guide for strandings. Sea Grant College Program, Texas A\&M University, Galveston, TX

Gulland FMD, Haulena M, Fauquier D, Langlois G, Lander ME, Zabka T, Duerr R (2002) Domoic acid toxicity in California sea lions (Zalophus californianus): clinical signs, treatment and survival. Vet Rec 150:475-480

> Haines AM, Tewes ME, Laack LL (2005) Survival and sources of mortality in ocelots. J Wildl Manag 69:255-263

> Heise K, Barrett-Lennard LG, Saulitis E, Matkin C, Bain D (2003) Examining the evidence for killer whale predation on Steller sea lions in British Columbia and Alaska. Aquat Mamm 29:325-334

> Henssge C (1988) Death time estimation in case work I. The rectal temperature time of death nomogram. Forensic Sci Int 38:209-236 
Henssge C (1995) Temperature-based methods II. In: Henssge C, Knight B, Krompecher T, Medea B, Nokes L (eds) The estimation of the time since death in the early postmortem period. Edward Arnold, London, p 46-105

Horning M, Hill RD (2005) Designing an archival satellite transmitter for life-long deployments on oceanic vertebrates: the Life History Transmitter. IEEE J Oceanic Eng 30:807-817

Horning M, Haulena M, Tuomi PA, Mellish JE (2008) Intraperitoneal implantation of life-long telemetry transmitters in otariids. BMC Vet Res 4:51, available at www. biomedcentral.com/1746-6148/4/51

Johnson DH (1979) Estimating nest success: the Mayfield method and an alternative. Auk 96:651-661

Loughlin TR, York AE (2000) An accounting of the sources of Steller sea lion, Eumetopias jubatus, mortality. Mar Fish Rev 62:40-45

Mall G, Eckl M, Sinicina I, Peschel O, Hubig M (2005) Temperature-based death time estimation with only partially known environmental conditions. Int J Leg Med 119:185-194

Maniscalco JM, Matkin CO, Maldini D, Calkins DG, Atkinson S (2007) Assessing killer whale predation on Steller sea lions from field observations in Kenai Fjords, Alaska. Mar Mamm Sci 23:306-321

Marshall TK, Hoare FE (1962a) I. Estimating the time of death. The rectal cooling after death and its mathematical expression. J Forensic Sci 7:56-81

Marshall TK, Hoare FE (1962b) II. The use of the cooling formula in the study of post mortem body cooling. J Forensic Sci 7: 189-210

Marshall TK, Hoare FE (1962c) III. The use of the body temperature in estimating the time of death. J Forensic Sci 7: 211-221

Mayfield H (1961) Nesting success calculated from exposure. Wilson Bull 73:255-261

Mellish JE, Calkins DG, Christen DR, Horning M, Rea LD,

Editorial responsibility: Daniel Costa,

Santa Cruz, California, USA
Atkinson SK (2006) Temporary captivity as a research tool: comprehensive study of wild pinnipeds under controlled conditions. Aquat Mamm 32:58-65

> Mellish J, Thomton J, Horning M (2007) Physiological and behavioral response to intra-abdominal transmitter implantation in Steller sea lions. J Exp Mar Biol Ecol 351: 283-293

NMFS (National Marine Fisheries Service) (2008) Recovery plan for the Steller sea lion (Eumetopias jubatus). Revision. National Marine Fisheries Service, Silver Spring, MD

Neely RD, Campbell RW (1973) A system for gathering small mammal mortality data. US Forest Service Research Paper NE-280:1-6

- Petrauskas L, Atkinson S, Gulland F, Mellish J, Horning M (2008) Monitoring glucocorticoid response to rehabilitation and research procedures in California and Steller sea lions. J Exp Zool 309A:73-82

Springer AM, Estes JA, van Vliet GB, Williams TM and others (2003) Sequential megafaunal collapse in the North Pacific Ocean: An ongoing legacy of industrial whaling? Proc Natl Acad Sci USA 100:12223-12228

> Thomton JD, Mellish JE, Hennen DR, Horning M (2008) Juvenile Steller sea lion foraging behavior following temporary captivity. Endang Species Res 4:195-203

> Vreeland JK, Diefenbach DR, Wallingford BD (2004) Survival rates, mortality causes, and habitats of Pennsylvania white-tailed deer fawns. Wildl Soc Bull 32:542-553

White GC, Burnham KP (1999) Program MARK: survival estimation from populations of marked animals. Bird Study 46(Suppl):120-138

Williams TM, Estes JA, Doak DF, Springer AM (2004) Killer appetites: assessing the role of predators in ecological communities. Ecology 85:3373-3384

Yaeger DP, Ultsch GR (1989) Physiological regulation and conformation: a BASIC program for the determination of critical points. Physiol Zool 80:3-8

Submitted: March 19, 2009; Accepted: July 11, 2009

Proofs received from author(s): September 1, 2009 